\title{
RESEARCH
}

\section{Papillary thyroid carcinoma behavior: clues in the tumor microenvironment}

\author{
Kensey Bergdorf*, Donna C Ferguson*, Mitra Mehrad, Kim Ely, Thomas Stricker and Vivian L Weiss \\ Department of Pathology, Microbiology and Immunology, Vanderbilt University Medical Center, Nashville, Tennessee, USA \\ Correspondence should be addressed to T Stricker or V L Weiss: thomas.stricker@vumc.org or Vivian.l.weiss@vanderbilt.edu \\ *(K Bergdorf and D C Ferguson contributed equally to this work)
}

\begin{abstract}
The prevalence of thyroid carcinoma is increasing and represents the most common endocrine malignancy, with papillary thyroid carcinoma (PTC) being the most frequent subtype. The genetic alterations identified in PTCs fail to distinguish tumors with different clinical behaviors, such as extra-thyroidal extension and lymph node metastasis. We hypothesize that the immune microenvironment may play a critical role in tumor invasion and metastasis. Computational immunogenomic analysis was performed on 568 PTC samples in The Cancer Genome Atlas using CIBERSORT, TIMER and TIDE deconvolution analytic tools for characterizing immune cell composition. Immune cell infiltrates were correlated with histologic type, mutational type, tumor pathologic T stage and lymph node $N$ stage. Dendritic cells (DCs) are highly associated with more locally advanced tumor T stage $\left(\mathrm{T} 3 / \mathrm{T} 4\right.$, odds ratio $\left.(\mathrm{OR})=2.6, \mathrm{Cl}=1.4-4.5, P=5.4 \times 10^{-4}\right)$. Increased dendritic cells $\left(\mathrm{OR}=3.4, \mathrm{Cl}=1.9-6.3, P=5.5 \times 10^{-5}\right)$ and neutrophils $(\mathrm{OR}=10.5, \mathrm{Cl}=2.7-44$, $P=8.7 \times 10^{-4}$ ) significantly correlate with lymph node metastasis. In addition, dendritic cells positively correlate with tall cell morphology $\left(\mathrm{OR}=4.5, \mathrm{Cl}=1.6-13, P=4.9 \times 10^{-3}\right)$ and neutrophils negatively correlate with follicular morphology $\left(\mathrm{OR}=1.3 \times 10^{-3}, \mathrm{Cl}=\right.$ $5.3 \times 10^{-5}-0.031, P=4.1 \times 10^{-5}$ ). TIDE analysis indicates an immune-exclusive phenotype that may be mediated by increased galectin-3 found in PTCs. Thus, characterization of the PTC immune microenvironment using three computational platforms shows that specific immune cells correlate with mutational type, histologic type, local tumor extent and lymph node metastasis. Immunologic evaluation of PTCs may provide a better indication of biologic behavior, resulting in the improved diagnosis and treatment of thyroid cancer.
\end{abstract}
Key Words
- tumor immunology
- papillary thyroid carcinoma
- thyroid cancer
- immunogenomics
- RNA sequencing

Endocrine-Related Cancer (2019) 26, 601-614

\section{Introduction}

The incidence of thyroid malignancy in the United States is rapidly increasing, with thyroid cancer projected to be the fourth leading cancer diagnosis by 2030 (Rahib et al. 2014, Galdiero et al. 2016). However, morphologic assessment of the primary tumor fails to predict the likelihood of metastatic or recurrent disease. We predict that the thyroid tumor immune microenvironment may play an important role in tumor behavior and may provide clues for improved targeted therapies.

Current studies on the immune microenvironment of thyroid tumors are often contradictory. Generally, tumorinfiltrating lymphocytes are known to enhance tumor immunity. However, studies in thyroid cancer have shown variable prognostic significance (Matsubayashi et al. 1995,
C) 2019 Society for Endocrinology Published by Bioscientifica Ltd. Printed in Great Britain 
Lundgren et al. 2006, French et al. 2010, Cunha et al. 2012, Yu et al. 2013, Galdiero et al. 2016). As early as 1995, TILs were shown to be associated with reduced extra-thyroidal extension (Matsubayashi et al. 1995), but subsequent studies of TILs did not consistently demonstrate a positive effect on tumor behavior (Lundgren et al. 2006, French et al. 2010). Similarly, differentiated thyroid carcinoma patients with background chronic lymphocytic thyroiditis and increased CD8 $\mathrm{T}$ cell tumor infiltration show increased disease-free survival (Cunha et al. 2012). However, CD8 $\mathrm{T}$ cell infiltration with COX2 expression may predict relapse in these same tumors (Cunha et al. 2015). Dendritic cells (DCs) are also traditionally thought to have an important role in antigen presentation and tumor immunity. However, there are subsets of DCs that are immunosuppressive and enhance tumor growth. In the thyroid, DCs are increased in papillary thyroid carcinomas (PTCs) over benign parenchyma (Tsuge et al. 2005, Ugolini et al. 2014, Galdiero et al. 2016), but it is unclear whether these DCs are beneficial in the tumor microenvironment. Tumorassociated macrophages (TAMs) are generally thought to be tumor enhancing, which is supported in thyroid studies that suggest they are present in more aggressive tumors (Cunha et al. 2012, Kim 2013, Fang et al. 2014, Jung et al. 2015, Galdiero et al. 2016). Finally, neutrophils have recently been shown to enhance metastatic disease in other tumor types (Wculek \& Malanchi 2015, Hiramatsu et al. 2018, Soler-Cardona et al. 2018), but their role in thyroid cancer progression is unknown.

The development of The Cancer Genome Atlas (TCGA) in 2006 provided the scientific community with a unique view into many aspects of tumor biology, including the patient immune response. This publically available data set provides sequencing information for over 20,000 primary cancer and matched normal samples from patients with 33 cancer types. TCGA is a tremendous resource, providing researchers with essential tumor data including genomic/epigenomic, transcriptomic and proteomic information. For thyroid cancer, transcriptomic data are available for 568 PTCs. Recent TCGA evaluation of the thyroid immune microenvironment suggests that certain subsets of aggressive tumors are immunologically distinct (Kim et al. 2018, Na \& Choi 2018). In this paper, we present the first evaluation of a large thyroid tumor cohort of 568 PTCs from TCGA that defines the key immune cell infiltrates within the tumor microenvironment that may be involved in aggressive tumor behavior. Identification of the specific infiltrates associated with aggressive features will lead to improved and targeted immunotherapy for the treatment of aggressive thyroid carcinomas.

\section{Materials and methods}

\section{TCGA computational analysis}

The results presented here are based upon data generated by the TCGA Research Network (http://cancergenome. nih.gov/). Computational immunogenomic analysis was performed on RNA-sequencing data from 568 PTCs in TCGA. Mutational data were available for 502 PTCs in TCGA. Patient characteristics are presented in Table 1. The CIBERSORT deconvolution analytic tool for characterizing cellular composition (Newman et al. 2015) calculates immunologic cell fractions for 22 hematopoietic cell types such that all of the individual fractions for each immune cell type sum to 1 (https:// cibersort.stanford.edu/). For each tumor, CIBERSORT calculated a global $P$ value for the immune cell fraction result based on the statistical probability of the presence of immune cells in the sample. All samples, regardless of

Table 1 The Cancer Genome Atlas (TCGA) patient characteristics.

\begin{tabular}{|c|c|c|}
\hline & $\begin{array}{l}\text { With mutation } \\
\text { data }(N=502)\end{array}$ & $\begin{array}{l}\text { Without mutation } \\
\text { data }(N=568)\end{array}$ \\
\hline Patient characteristics & $\begin{array}{l}\text { Number of } \\
\text { patients (\%) }\end{array}$ & $\begin{array}{l}\text { Number of } \\
\text { patients (\%) }\end{array}$ \\
\hline Average age & 47 & 47 \\
\hline Age range & $15-89$ & $15-89$ \\
\hline Number male & $129(26 \%)$ & $149(26 \%)$ \\
\hline Number female & $352(70 \%)$ & $396(70 \%)$ \\
\hline Gender unknown & $21(4 \%)$ & $23(4 \%)$ \\
\hline Morphologic type & Number of tumors & Number of tumors \\
\hline Classical histotype & $339(68 \%)$ & $393(69 \%)$ \\
\hline Follicular histotype & $98(19 \%)$ & $105(18 \%)$ \\
\hline Tall cell histotype & $35(7 \%)$ & $38(7 \%)$ \\
\hline $\begin{array}{l}\text { Other/unknown } \\
\text { histotype }\end{array}$ & $30(6 \%)$ & $32(6 \%)$ \\
\hline Mutational status & Number of tumors & Number of tumors \\
\hline BRAF & $291(58 \%)$ & $\mathrm{N} / \mathrm{A}$ \\
\hline RAS & $45(9 \%)$ & $\mathrm{N} / \mathrm{A}$ \\
\hline Neither & $169(33 \%)$ & $\mathrm{N} / \mathrm{A}$ \\
\hline Tumor stage & Number of tumors & Number of tumors \\
\hline $\mathrm{T} 1 / 2$ & $293(58 \%)$ & $314(55 \%)$ \\
\hline $\mathrm{T} 3 / 4$ & $186(37 \%)$ & $229(40 \%)$ \\
\hline Unknown & $23(5 \%)$ & $25(5 \%)$ \\
\hline Lymph node stage & Number of tumors & Number of tumors \\
\hline No LN involvement & $223(44 \%)$ & $243(43 \%)$ \\
\hline LN involvement & $212(42 \%)$ & $251(44 \%)$ \\
\hline Unknown & $67(14 \%)$ & $74(13 \%)$ \\
\hline Distant metastases & 11 & 14 \\
\hline Patients deceased & 14 & 18 \\
\hline
\end{tabular}

Patient characteristics are presented for 502 patients with mutation data available (DNA next-generation sequencing) and 568 patients without mutation data available (RNA next-generation sequencing). 
the $P$ value, were included in this analysis. Even those samples with $P$ value $>0.05$ may be important, as they may represent samples with low immune cell infiltrate. Of note, the CIBERSORT program normalized the data in relative space, so that the immune cell fractions combined were equal to 1 . The recommended/default CIBERSORT settings were used including the 100 permutations and disabled quantile normalization for RNA-sequencing data. The second analytic tool used was the TIMER, which is another deconvolution analytic tool that calculates the abundance of six immune cell types (B cells, CD4+ T cells, CD8+ T cells, neutrophils, macrophages and dendritic cells; https://cistrome.shinyapps.io/timer/) (Li et al. 2016, 2017). All 568 TCGA PTCs were included in this analysis. TIMER has built in normalization and permutations, and thyroid cancer was the selected tumor type. Finally, the TIDE analytic tool was used for analysis of responsiveness to checkpoint inhibitor therapies, as well as $\mathrm{T}$ cell exclusion and $\mathrm{T}$ cell dysfunction analysis (http://tide.dfci. harvard.edu/) (Jiang et al. 2018). TIDE requires that each gene be normalized prior to upload. This normalization was performed on the data per TIDE's documentation recommendations.

Clinicopathologic characteristics studied for these patients include age at diagnosis, histologic subtype, tumor pathologic $\mathrm{T}$ stage, lymph node (LN) $\mathrm{N}$ stage and mutational analysis. Staging was based on the American Joint Committee on Cancer $7^{\text {th }}$ Edition. The mutations evaluated include some of the most commonly mutated genes in the TCGA data (502 PTCs); however, only BRAF and $R A S$ mutations were frequent enough to perform downstream analysis of that mutational subgroup (Table 1).

GEPIA, the Gene Expression Profiling Interactive Analysis tool, was used to generate boxplots of LGALS3 expression from the THCA dataset compared to TCGA data from normal (non-tumor) TCGA and GTEx data. The $\left|\log _{2} \mathrm{FC}\right|$ cutoff was set at 1 and the $P$ value cutoff was 0.01 .

\section{Statistical analysis}

Logistic regression was conducted to analyze associations between the immune cell fractions with mutational status, tumor pathologic $\mathrm{T}$ stage and $\mathrm{LN} \mathrm{N}$ stage. For all TIMER analyses, all six immune cell types (dendritic cells, CD8 T cells, CD4 T cells, macrophages, B cells and neutrophils) were included as co-variates. For CIBERSORT, 15/22 immune cell types (naïve B cells, memory B cells, plasma cells, CD8 T cells, resting CD4 memory T cells, activated CD4 memory T cells, follicular helper T cells, regulatory T cells, gamma delta T cells, M0 macrophages, M1 macrophages, M2 macrophages, resting dendritic cells, activated dendritic cells and neutrophils) were included as co-variates corresponding to the major immune cell types identified in TIMER. Naïve CD4 $\mathrm{T}$ cells were excluded from CIBERSORT analyses because the value was 0 for all 568 PTCs. Mast cells, eosinophils, monocytes and NK cells were excluded from CIBERSORT analyses since these infiltrates could not be confirmed using the TIMER deconvolution tool. The CIBERSORT immune cell fractions were converted to percentages prior to analysis. For each immune cell type we performed a multivariate logistic regression with the infiltrates as continuous variables. No adjustments were made for multiple statistical testing. The odds ratio is presented as a $1 \%$ increase in immune cell fraction for CIBERSORT and a one-unit increase in the infiltration level for TIMER. Morphologic subtype was also included as a co-variate for mutational analyses and stage analyses and is presented in the Supplementary data.

For the dependent variables, pathologic tumor $\mathrm{T}$ stage was divided into low (T1 and T2) and high (T3 and T4) stage and was treated as a dichotomous variable. This distinction was made based on tumor size $>4 \mathrm{~cm}$ and/or the presence of extra-thyroidal extension (T3 and T4) versus smaller size with the absence of extra-thyroidal extension (T1 and T2). For the LN stage, this category was classified as no metastasis (NO) or presence of LN metastasis (>NO) and treated as a dichotomous variable.

Multinomial logistic regression was used for analysis of morphologic subtypes, as histologic types are not a binary classification. This analysis used classical PTC histology as the baseline category. The same immunologic co-variates were used for this analysis.

Downstream analysis of the activated dendritic cell high and activated dendritic cell low cohorts were performed using a subset of samples with CIBERSORT $P$ value $<0.05$, as these represent samples with absolute immune infiltration that is not close to zero (131 samples). Genes with a mean expression of less than $\log _{2}$ $\mathrm{FPKM}=2.5$ were removed. Surrogate Variable Analysis was performed on the resulting gene expression matrix, and then surrogate variables were regressed from the gene expression matrix. Differential gene expression was then determined using a gene-by-gene linear model of the form $y \sim D C \_s t a t u s+B R A F \_s t a t u s$, where DC_status=high or low DC as a factor and BRAF_status = mutated or nonmutated as a factor. False discovery rate was controlled by FDR using the $q$ value package in R. We used the Database 
for Annotation, Visualization, and Integrated Discovery (DAVID) to identify pathways and biological processes enriched in the differential expression gene list. Gene lists were uploaded to the DAVID website as ensembl symbols, and the whole transcriptome was used as a background. The functional clustering tool was used to identify the most enriched terms. Pathway analysis was performed using DAVID (https://david.ncifcrf.gov/) and ensembl gene names. Heatmaps were produced in $\mathrm{R}$ using heatmap.2.

\section{Institutional patient selection and analysis for immunohistochemistry}

An additional cohort of patients was collected from Vanderbilt University Medical Center archives to confirm the TCGA computational analysis. In this Institutional Review Board approved study, files from 2008 to 2017 containing diagnoses of classical papillary thyroid carcinoma (PTC, $N=20$ ), follicular variant of PTC (FVTPC, $N=12$ ) and non-invasive follicular thyroid neoplasm with papillary-like nuclear features (NIFTP, $N=11$ ) resection diagnoses were identified. All cases of NIFTP were included in the analysis as well as 20 sequential cases of infiltrative classical and follicular variants of PTC. Patient characteristics are presented in Supplementary Table 1 (see section on supplementary data given at the end of this article). H\&E sections from surgical resection specimens were reviewed by three pathologists with head and neck expertise (KE, MM, VW) to confirm the histopathologic diagnoses. Some historic encapsulated FVPTC cases were re-classified as NIFTP based on the criteria proposed by Nikiforov et al. (2016). Only lesions that were entirely submitted for histologic evaluation were included. When there was disagreement among the pathologists, a fourth head and neck specialist was consulted.

\section{Immunohistochemistry}

Four micron sections from 11 NIFTPs and 12 FVPTCs were evaluated by $\mathrm{H} \& \mathrm{E}$ and immunohistochemistry (IHC) for expression of Galectin-3 (GAL3, sc-23938, Santa Cruz Biotechnology, 1:1000 dilution). Four micron sections from 20 classical PTCs were evaluated by H\&E and IHC for expression of FoxP3 (236A/E7, eBioscience, Inc., 1:100 dilution), CD8 (MM39-10, StatLab) and CD4 (PA0427, Leica). IHC staining was performed according to manufacturer's protocols in the Translational Pathology Shared Resource Core at Vanderbilt University Medical Center. Unstained slides were first deparaffinized by routine methods. For antigen retrieval, slides were heated in citrate buffer ( $\mathrm{pH} 6.0$ ) at $100^{\circ} \mathrm{C}$ for $20 \mathrm{~min}$ or in EDTA (pH 9.0) at $98^{\circ} \mathrm{C}$ for $20 \mathrm{~min}$, followed by a 10 -min cool down to room temperature. All slides were then quenched with $0.03 \%(\mathrm{v} / \mathrm{v}) \mathrm{H}_{2} \mathrm{O}_{2}$ with $\mathrm{NaN}_{3}$ for $5 \mathrm{~min}$. Slides were blocked for $20 \mathrm{~min}$ with serum-free protein block (Dako), followed by application of primary antibodies. Slides were then incubated with Evision + HRP-labeled polymer (Dako) for $30 \mathrm{~min}$, followed by $5 \mathrm{~min}$ incubation with DAB (Dako). Immunohistochemical stains were evaluated and scored on a scale of $0-3$ for maximum intensity of staining. The pattern of GAL3 staining was categorized as subcapsular or diffuse, and analysis was performed using $2 \times 3$ Fisher's exact tests. The pattern of CD8, CD4, and FoxP3 infiltration was categorized as intra-tumoral $(>10 \%$ positive cells in the tumor) or peripheral $(<10 \%$ positive cells within the tumor, $>10 \%$ positive cells in the peripheral stroma) based on a standardized methodology for assessing tumor-infiltrating lymphocytes (Hendry et al. 2017a,b). Of note, weak FoxP3 staining was observed in the tumor cells but was excluded from this analysis, as only strong nuclear FoxP3 positivity within lymphocytes was scored as positive.

\section{Results}

\section{Immunologic cell fraction characterization and correlation with histology and mutational status}

We hypothesized that different PTC histopathologic subtypes would have different compositions of immune cell infiltration. We therefore chose two publicly available computational tools to estimate the specific immune cell types present in each tumor within the Cancer Genome Atlas Cohort ( $N=568$ PTCs). These two computational tools, CIBERSORT and TIMER, use RNA-sequencing data to estimate the immune infiltrate in each sample using unique gene signatures, determined by the creators of each tool (Abbas et al. 2005, Li et al. 2016, 2017). CIBERSORT calculates the immune cell fractions of 22 unique immune cells subtypes and normalizes the data such that all fractions sum to 1 . TIMER calculates the immune cell infiltrate of six unique immune cell subtypes.

Using classical histology as the baseline category, CIBERSORT data demonstrated that the more clinically indolent follicular variant histology had a significant negative correlation with TAMs $(\mathrm{M} 0: \mathrm{OR}=0.93, \mathrm{CI}=$ 0.89-0.96, $P=1.3 \times 10^{-5} ; \mathrm{M} 1: \mathrm{OR}=0.91, \mathrm{CI}=0.83-0.99$, $P=0.023$ ) and DCs (resting: $\mathrm{OR}=0.90, \mathrm{CI}=0.85-0.95$, $P=3.1 \times 10^{-4}$; activated: $\left.\mathrm{OR}=0.86, \mathrm{CI}=0.76-0.97, P=0.014\right)$. 
Analysis of CIBERSORT data also indicated that the more clinically aggressive tall cell variant had a slight positive correlation with the resting DC fraction (OR=1.1, $\mathrm{CI}=1.0-1.2, \quad P=0.042)$. TIMER data analysis demonstrated a negative correlation between follicular variant histology and immune infiltrate including DCs $\left(\mathrm{OR}=0.057, \mathrm{CI}=0.019-0.18, P=5.1 \times 10^{-7}\right)$, CD8 T cells $\left(\mathrm{OR}=0.22, \mathrm{CI}=0.080-0.61, P=3.4 \times 10^{-3}\right)$ and neutrophils $\left(\mathrm{OR}=1.3 \times 10^{-3}, \quad \mathrm{CI}=5.3 \times 10^{-5}-0.031, \quad P=4.1 \times 10^{-5}\right)$. Similar to CIBERSORT, TIMER showed the more clinically aggressive tall cell variant of PTC to be positively correlated with DCs $\left(\mathrm{OR}=4.5, \mathrm{CI}=1.6-13, P=4.9 \times 10^{-3}\right.$; Table 2$)$.

Next, we assessed the immune fractions in relation to BRAF and RAS mutational status (Table 3). Evaluation of the 502 PTCs using CIBERSORT indicated that BRAF mutational status correlated with increased immune cell fractions for naïve $\mathrm{B}$ cells, regulatory $\mathrm{T}$ cells, macrophages and dendritic cells. Follicular helper T cells negatively correlated with $B R A F$ mutation. In contrast, RAS mutants correlated with decreased immune cell fractions of naïve $\mathrm{B}$ cells, macrophages and dendritic cells. CD8 $\mathrm{T}$ cells and follicular helper $\mathrm{T}$ cells showed a positive correlation with RAS mutations. Similarly, TIMER indicated that $B R A F$ mutational status correlated with significantly increased DCs (Supplementary Fig. 1), CD8 T cells, macrophages, B cells and neutrophils. In contrast, RAS mutation correlated with significantly decreased DCs (Supplementary Fig. 1), CD8 T cells, CD4 $\mathrm{T}$ cells, B cells and neutrophils (Table 3 ). These data were also analyzed to include morphologic subtype as a co-variate with the majority of immune cell types listed above remaining significantly correlated with mutational status (Supplementary Table 2). Overall, these data demonstrate that $B R A F$-mutant tumors are generally immune cell rich, while $R A S$-mutant tumors are immune cell poor.

Finally, we evaluated the TCGA data to investigate the relationship between immune cell infiltrates in the tumor microenvironment and age, gender, survival and tumor mutational burden (TMB). There was no correlation between gender and immune infiltration. Increasing age correlated with an overall decreased immune infiltrate. Survival assessment using a Cox proportional hazard model with the immune infiltrates as co-variates showed no statistical significance. Overall PTCs in the TCGA had a very low $\mathrm{TMB}$ of $<1$ mutation/Mb. In the TCGA PTCs, there was no correlation between infiltration of immune cell subtypes and total mutations.

\section{Infiltrates and pathologic tumor stage in PTCs}

We next evaluated whether changes in immune infiltrates were associated with pathologic tumor $\mathrm{T}$ stage (Fig. 1, Table 4, N=568). CIBERSORT demonstrated increased activated DCs in tumors with more locally advanced tumor $\mathrm{T}$ stage $\left(\mathrm{OR}=1.2, \mathrm{CI}=1.1-1.3, P=3.7 \times 10^{-5}\right.$, using the American Joint Committee on Cancer $7^{\text {th }}$ Edition) and decreased follicular helper $\mathrm{T}$ cells $\left(\mathrm{T}_{\mathrm{FH}}\right)$ with more locally advanced $\mathrm{T}$ stage $(\mathrm{OR}=0.93, \mathrm{CI}=0.87-0.98, P=0.014)$. TIMER analysis generated similar results, with increased DCs associating with advanced $\mathrm{T}$ stage $(\mathrm{OR}=2.6, \mathrm{CI}=$ 1.5-4.5, $P=5.4 \times 10^{-4}$, Fig. 1, Table 4). Using TIMER, there was no significant correlation with CD4 T cells and tumor T stage.

CIBERSORT also showed a slight correlation between TAMs and tumor T stage. While there have been several reports of a correlation between TAMs and tumor immunity (Ryder et al. 2008, Qing et al. 2012), TIMER did not confirm an association between macrophages and tumor stage. These data were also analyzed to include morphologic subtype as a co-variate with all the immune cells types listed above remaining significantly correlated with mutational status (Supplementary Table 3).

\section{Infiltrates and pathologic LN stage in PTCs}

Another important factor in thyroid cancer management and treatment is the presence of LN metastasis. Using CIBERSORT $(N=568)$, resting DCs showed a slight positive correlation with $\mathrm{LN}$ metastasis $(\mathrm{OR}=1.1$, $\mathrm{CI}=1.0-1.1, P=0.019)$. TIMER confirmed the presence of significantly increased DCs in tumors with LN metastasis $\left(\mathrm{OR}=3.4, \quad \mathrm{CI}=1.9-6.3, \quad P=5.5 \times 10^{-5}\right) \quad$ and also demonstrated increased CD8 $\mathrm{T}$ cells $(\mathrm{OR}=2.1, \mathrm{CI}=$ 1.1-4.0, $P=0.029)$ and robust neutrophil infiltrate $\left(\mathrm{OR}=10.5, \mathrm{CI}=2.7-44, P=8.7 \times 10^{-4}\right)$ in tumors with LN metastases (Fig. 2, Table 5). CIBERSORT did not show a significant correlation with CD8 T cells. A slight correlation was seen with naïve B cells and M0 macrophages using CIBERSORT, but TIMER failed to confirm any $\mathrm{B}$ cell or macrophage association. These data were also analyzed to include morphologic subtype as a co-variate and found that for CIBERSORT naïve $B$ cells remained significantly correlated with LN stage and for TIMER DCs and neutrophils remained significantly associated with LN stage (Supplementary Table 4). (c) 2019 Society for Endocrinology Published by Bioscientifica Ltd. Printed in Great Britain 
Table 2 Relationship of immune cell fractions with histologic subtype using CIBERSORT and TIMER $(N=568)$.

\begin{tabular}{|c|c|c|c|}
\hline Cell type & OR & $95 \% \mathrm{Cl}$ & $P$ value \\
\hline \multicolumn{4}{|l|}{ CIBERSORT } \\
\hline \multicolumn{4}{|l|}{ Follicular variant PTC } \\
\hline Naïve B cells & 0.95 & $0.90-1.0$ & 0.038 \\
\hline Memory B cells & 0.93 & $0.82-1.1$ & 0.26 \\
\hline Plasma cells & 0.97 & $0.92-1.0$ & 0.38 \\
\hline CD8 T cells & 1.0 & $0.97-1.1$ & 0.71 \\
\hline $\begin{array}{l}\text { Resting CD4 memory } \\
\text { T cells }\end{array}$ & 0.97 & $0.93-1.0$ & 0.24 \\
\hline $\begin{array}{l}\text { Activated CD4 memory } \\
\text { T cells }\end{array}$ & 0.65 & $0.41-1.0$ & 0.068 \\
\hline Follicular helper T cells & 1.1 & $0.97-1.1$ & 0.25 \\
\hline Regulatory T cells & 0.96 & $0.87-1.1$ & 0.40 \\
\hline Gamma delta T cells & 0.96 & $0.86-1.1$ & 0.45 \\
\hline M0 macrophages & 0.93 & $0.89-0.96$ & $1.3 \times 10^{-5}$ \\
\hline M1 macrophages & 0.91 & $0.83-0.99$ & 0.023 \\
\hline M2 macrophages & 1.0 & $0.96-1.0$ & 1.0 \\
\hline Resting dendritic cells & 0.90 & $0.85-0.95$ & $3.1 \times 10^{-4}$ \\
\hline Activated dendritic cells & 0.86 & $0.76-0.97$ & 0.014 \\
\hline Neutrophils & 0.53 & $0.22-1.3$ & 0.16 \\
\hline \multicolumn{4}{|l|}{ Tall cell variant PTC } \\
\hline Naïve B cells & 1.0 & $0.97-1.1$ & 0.27 \\
\hline Memory B cells & 0.90 & $0.72-1.1$ & 0.36 \\
\hline Plasma cells & 1.0 & $0.93-1.1$ & 0.71 \\
\hline CD8 T cells & 0.93 & $0.85-1.0$ & 0.12 \\
\hline $\begin{array}{l}\text { Resting CD4 memory } \\
\text { T cells }\end{array}$ & 1.0 & $0.92-1.1$ & 0.97 \\
\hline $\begin{array}{l}\text { Activated CD4 memory } \\
\text { T cells }\end{array}$ & 1.2 & $0.83-1.7$ & 0.36 \\
\hline Follicular helper T cells & 0.98 & $0.86-1.1$ & 0.70 \\
\hline Regulatory T cells & 1.1 & $1.0-1.3$ & 0.071 \\
\hline Gamma delta T cells & 0.85 & $0.65-1.1$ & 0.25 \\
\hline M0 macrophages & 1.0 & $0.95-1.1$ & 0.80 \\
\hline M1 macrophages & 1.1 & $0.91-1.2$ & 0.50 \\
\hline M2 macrophages & 0.94 & $0.87-1.0$ & 0.16 \\
\hline Resting dendritic cells & 1.1 & $1.0-1.2$ & 0.042 \\
\hline Activated dendritic cells & 0.97 & $0.82-1.1$ & 0.72 \\
\hline Neutrophils & 1.9 & $0.86-4.0$ & 0.12 \\
\hline \multicolumn{4}{|l|}{ TIMER } \\
\hline \multicolumn{4}{|l|}{ Follicular variant PTC } \\
\hline DCs & 0.057 & $0.019-0.18$ & $5.1 \times 10^{-7}$ \\
\hline CD8 T cells & 0.22 & $0.080-0.61$ & $3.4 \times 10^{-3}$ \\
\hline CD4 T cells & 0.14 & $6.6 \times 10^{-3}-3.1$ & 0.21 \\
\hline Macrophages & 0.58 & $0.13-2.6$ & 0.48 \\
\hline B cells & 0.34 & $0.11-1.1$ & 0.063 \\
\hline Neutrophils & $1.3 \times 10^{-3}$ & $5.3 \times 10^{-5}-0.031$ & $4.1 \times 10^{-5}$ \\
\hline \multicolumn{4}{|l|}{ Tall cell variant PTC } \\
\hline Cell type & & & \\
\hline DCs & 4.5 & $1.6-13$ & $4.9 \times 10^{-3}$ \\
\hline CD8 T cells & 0.50 & $0.13-1.9$ & 0.32 \\
\hline CD4 T cells & 0.15 & $1.8 \times 10^{-3}-12$ & 0.40 \\
\hline Macrophages & 0.60 & $0.020-18$ & 0.77 \\
\hline B cells & 1.1 & $0.19-5.9$ & 0.94 \\
\hline Neutrophils & 4.5 & $0.51-39$ & 0.18 \\
\hline
\end{tabular}

A multinomial linear regression is presented with classical morphology as the baseline category. Cases of follicular morphology and tall cell morphology are evaluated for immune infiltrates using CIBERSORT and TIMER. The odds ratio is presented as a $1 \%$ increase in immune cell fraction for CIBERSORT and a one-unit increase in the infiltration level for TIMER. Bold indicates statistical significance.

\section{Immune suppression and exclusion in PTCs}

Tumor Immune Dysfunction and Exclusion (TIDE) analysis (Jiang et al. 2018) was performed on the TCGA cohort of 502 PTCs. TIDE is another publicly available bioinformatics tool that uses RNA-sequencing data to assess the immune infiltration of a given tumor based on gene expression. This tool generates information on the patient's susceptibility to checkpoint inhibitor therapies, the $T$ cell exclusion status of the tumor and the $\mathrm{T}$ cell dysfunction/exhaustion present in a tumor. The overall TIDE score predicts the susceptibility of the tumor to immune checkpoint blockade (Fig. 3A). Of the TCGA PTCs, 93\% (469/502) were determined unlikely to respond to current checkpoint blockade therapies. Interestingly, only $9.2 \%(46 / 502)$ of the tumors had gene signatures indicating $\mathrm{T}$ cell dysfunction (Fig. 3B), while 95\% (477/502) exhibited expression profiles consistent with $\mathrm{T}$ cell exclusive phenotype (Fig. 3C).

TIDE is currently only validated for melanoma and non-small-cell lung cancer. In order to validate the computational findings of TIDE, we aimed to confirm these results by performing IHC on a cohort of 20 classical PTCs at Vanderbilt University Medical Center (VUMC). We confirmed this phenomenon of T cell exclusion in our cohort of 20 classical PTCs using CD8, CD4 and FoxP3 immunohistochemistry. When observing the peripheral edge of each sample, $60 \%(12 / 20)$ demonstrated dense CD8 positivity, 90\% (18/20) demonstrated dense CD4 positivity and $85 \%(17 / 20)$ demonstrated dense FoxP3 positivity (Fig. 3D). The center of the tumor in the 20 PTCs analyzed was generally lymphocyte poor. These VUMC data in combination with the TCGA TIDE data indicate that functional $\mathrm{T}$ cells are present in the tumor microenvironment but are primarily located around the margins of the tumor, often with predominant lymphoid aggregates. We hypothesized that factors produced by the tumor cells, particularly at the tumor margins, were mediating this immune exclusion phenomenon.

\section{Galectin 3 potentially mediates T cell exclusion in PTCs}

Having demonstrated a significant correlation between DC infiltration and thyroid cancer histology/stage, we next investigated which genes were differentially expressed between the DC high and DC low groups. The TCGA thyroid expression data were subset for samples that had a significant $(P<0.05)$ CIBERSORT score https://erc bioscientifica com

https://doi.org/10.1530/ERC-19-0074 (c) 2019 Society for Endocrinology Published by Bioscientifica Ltd. Printed in Great Britain 
Table 3 Relationship of Immune cell fractions with $B R A F$ and RAS mutational status using CIBERSORT and TIMER $(N=502)$.

\begin{tabular}{|c|c|c|c|}
\hline Cell type & OR & $95 \% \mathrm{Cl}$ & $P$ value \\
\hline \multicolumn{4}{|l|}{ CIBERSORT } \\
\hline \multicolumn{4}{|l|}{ BRAF mutation } \\
\hline Naïve B cells & 1.1 & $1.1-1.2$ & $5.2 \times 10^{-5}$ \\
\hline Memory B cells & 0.98 & $0.89-1.1$ & 0.73 \\
\hline Plasma cells & 1.0 & $1.0-1.1$ & 0.13 \\
\hline CD8 T cells & 0.98 & $0.94-1.0$ & 0.21 \\
\hline $\begin{array}{l}\text { Resting CD4 memory } \\
\quad T \text { cells }\end{array}$ & 1.0 & $0.99-1.1$ & 0.13 \\
\hline $\begin{array}{l}\text { Activated CD4 } \\
\text { memory T cells }\end{array}$ & 1.3 & $0.95-1.7$ & 0.13 \\
\hline $\begin{array}{l}\text { Follicular helper } \\
\text { T cells }\end{array}$ & 0.92 & $0.86-0.98$ & 0.014 \\
\hline Regulatory T cells & 1.1 & $1.0-1.2$ & $3.8 \times 10^{-3}$ \\
\hline Gamma delta T cells & 1.0 & $0.93-1.1$ & 0.64 \\
\hline M0 macrophages & 1.1 & $1.0-1.1$ & $3.9 \times 10^{-4}$ \\
\hline M1 macrophages & 1.1 & $1.1-1.2$ & $7.5 \times 10^{-4}$ \\
\hline M2 macrophages & 1.0 & $0.99-1.1$ & 0.20 \\
\hline Resting dendritic cells & 1.1 & $1.1-1.1$ & $3.8 \times 10^{-5}$ \\
\hline $\begin{array}{l}\text { Activated } \\
\text { dendritic cells }\end{array}$ & 1.2 & $1.1-1.3$ & $7.8 \times 10^{-4}$ \\
\hline Neutrophils & 0.76 & $0.39-1.3$ & 0.39 \\
\hline \multicolumn{4}{|l|}{ RAS mutation } \\
\hline Naïve B cells & 0.89 & $0.80-0.98$ & 0.028 \\
\hline Memory B cells & 0.92 & $0.76-1.1$ & 0.39 \\
\hline Plasma cells & 0.95 & $0.85-1.1$ & 0.38 \\
\hline CD8 T cells & 1.1 & $1.0-1.1$ & $3.9 \times 10^{-3}$ \\
\hline $\begin{array}{l}\text { Resting CD4 memory } \\
\text { T cells }\end{array}$ & 1.1 & $0.99-1.1$ & 0.10 \\
\hline $\begin{array}{l}\text { Activated CD4 } \\
\text { memory T cells }\end{array}$ & 0.33 & $0.044-0.88$ & 0.13 \\
\hline $\begin{array}{l}\text { Follicular helper } \\
\text { T cells }\end{array}$ & 1.13 & $1.0-1.3$ & 0.027 \\
\hline Regulatory T cells & 1.1 & $0.96-1.2$ & 0.20 \\
\hline Gamma delta T cells & 1.1 & $0.96-1.2$ & 0.15 \\
\hline M0 macrophages & 1.0 & $0.98-1.1$ & 0.55 \\
\hline M1 macrophages & 0.87 & $0.76-0.98$ & 0.023 \\
\hline M2 macrophages & 1.1 & $1.02-1.1$ & $6.9 \times 10^{-3}$ \\
\hline Resting dendritic cells & 0.92 & $0.83-0.99$ & 0.045 \\
\hline $\begin{array}{l}\text { Activated } \\
\text { dendritic cells }\end{array}$ & 0.84 & $0.71-0.96$ & 0.023 \\
\hline Neutrophils & 0.98 & $0.50-1.8$ & 0.94 \\
\hline \multicolumn{4}{|l|}{ TIMER } \\
\hline \multicolumn{4}{|l|}{ BRAF mutation } \\
\hline DCs & 42 & 19-101 & $\mathbf{2 . 0 \times 1 0 ^ { - 1 6 }}$ \\
\hline CD8 T cells & 7.3 & $3.4-17$ & $1.1 \times 10^{-6}$ \\
\hline CD4 T cells & 0.70 & $0.072-6.7$ & 0.76 \\
\hline Macrophages & 12 & $3.0-52$ & $6.1 \times 10^{-4}$ \\
\hline B cells & 3.1 & $1.1-9.0$ & 0.038 \\
\hline Neutrophils & 32 & $6.2-181$ & $5.6 \times 10^{-5}$ \\
\hline \multicolumn{4}{|l|}{ RAS mutation } \\
\hline DCs & $8.0 \times 10^{-3}$ & $7.0 \times 10^{-4}-0.051$ & $1.0 \times 10^{-5}$ \\
\hline CD8 T cells & 0.040 & $5.1 \times 10^{-3}-0.22$ & $6.2 \times 10^{-4}$ \\
\hline CD4 T cells & $1.3 \times 10^{-3}$ & $3.0 \times 10^{-6}-0.22$ & 0.019 \\
\hline Macrophages & 0.50 & $0.084-2.6$ & 0.39 \\
\hline B cells & $7.14 \times 10^{-6}$ & $5.7 \times 10^{-10}-5.6 \times 10^{-3}$ & $3.2 \times 10^{-3}$ \\
\hline Neutrophils & $1.3 \times 10^{-3}$ & $6.0 \times 10^{-6-0.094}$ & $7.0 \times 10^{-3}$ \\
\hline
\end{tabular}

The odds ratio is presented as a $1 \%$ increase in immune cell fraction for CIBERSORT and a one-unit increase in the infiltration level for TIMER. Bold indicates statistical significance. (in order to ensure inclusion of tumors with an immune infiltrate), and 805 genes differentially expressed between low activated DCs and high activated DCs were identified (FDR $<0.05)$. A DAVID analysis bioinformatics tool was then chosen to evaluate these differentially expressed genes. DAVID analyses are ideal for large gene sets and are designed to systematically extract meaningful biological data from large sets of gene expression. DAVID analysis of these genes showed enrichment for pathways involved in immunity (top cluster, enrichment score=9.9, Fig. 4A). Interestingly, a heatmap of the genes in these immunity signatures showed that high activated DC samples tended to have low expression of these genes, while samples with low activated DC have high expression (Fig. 4B). This result suggested that the DC signature is associated with an immune-exclusive or immunosuppressive milieu. A similar analysis was performed for samples with high and low $\mathrm{T}_{\mathrm{FH}}$, identifying 1149 differentially expressed genes $($ FDR $<0.05)$. DAVID analysis of these genes also showed enrichment for pathways involved in immunity (top cluster, enrichment score=11.1). A heatmap of the genes in these immunity signatures showed that high $\mathrm{T}_{\mathrm{FH}}$ samples tended to have high expression of these genes, while samples with low $\mathrm{T}_{\mathrm{FH}}$ have low expression (Fig. 4C). One of the differentially expressed genes in our DC immunity signature was lymphocyte-activation gene 3 (LAG3) (FDR, 0.0004). Galectin 3 (GAL3, encoded by $L G A L S 3)$ is expressed on many cell types throughout the body, is highly expressed by many thyroid cancer types (Chiu et al. 2010) and, among other functions, promotes immunosuppression by interacting with LAG3 on immune cells such as dendritic cells and CD8+ T cells (Kouo et al. 2015). We find that the LGALS3/LAG3 ratio was significantly higher in activated DC high versus activated DC low (Fig. 4D), suggesting that this mechanism may contribute to an immune exclusion environment.

GEPIA (Tang et al. 2017) was then used to evaluate the expression of LGALS3 within the TCGA cohort. GEPIA is a publicly available bioinformatics tool that lets you explore the gene expression in the TCGA RNA-sequencing data. Gene expression analysis of the TCGA PTCs using GEPIA revealed that the TCGA cohort significantly expressed more LGALS3 than normal thyroid tissues (Fig. 5A). The importance of GAL3 in PTC diagnosis has been widely investigated, and it has been documented that more aggressive variants of PTC express higher levels of LGALS3 (Chiu et al. 2010). https://erc.bioscientifica.com https://doi.org/10.1530/ERC-19-0074 (c) 2019 Society for Endocrinology Published by Bioscientifica Ltd. Printed in Great Britain 

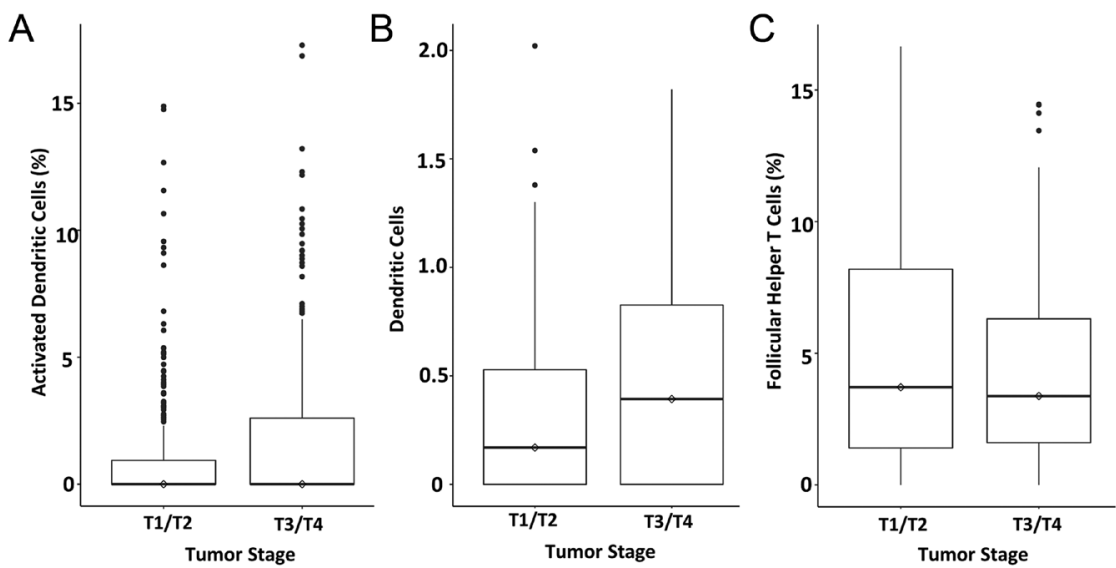

\section{Figure 1}

Distribution of immune cell infiltrate and pathologic tumor T stage $(N=568)$. (A) CIBERSORT distribution of activated dendritic cell fractions in low T stage (T1/T2) and high T stage (T3/T4) tumors. (B) TIMER distribution of dendritic cell fractions in low $\mathrm{T}$ stage $(\mathrm{T} 1 / \mathrm{T} 2)$ and high $\mathrm{T}$ stage (T3/T4) tumors. (C) CIBERSORT distribution of follicular helper $\mathrm{T}$ cell fractions in low $\mathrm{T}$ stage (T1/T2) and high T stage (T3/T4) tumors.
In order to confirm the increased LGALS3 gene expression identified in TCGA using GEPIA, we collected a cohort of VUMC infiltrative follicular variant PTCs (FVPTCs) and the more indolent non-invasive follicular thyroid neoplasms with papillary-like nuclear features (NIFTPs) to perform GAL3 immunohistochemistry. We evaluated GAL3 immunohistochemical expression in

Table 4 Relationship of Immune cell fractions with pathologic tumor T stage using CIBERSORT and TIMER $(N=568)$.

\begin{tabular}{l}
\hline T Stage \\
\hline CIBERSORT analysis \\
Naïve B cells \\
Memory B cells \\
Plasma cells \\
CD8 T cells \\
Resting CD4 memory \\
T cells \\
Activated CD4 memory \\
T cells \\
Follicular helper T cells \\
Regulatory T cells \\
Gamma delta T cells \\
M0 macrophages \\
M1 macrophages \\
M2 macrophages \\
Resting dendritic cells \\
Activated dendritic cells \\
Neutrophils \\
TIMER analysis \\
DCs \\
CD8 T cells \\
CD4 T cells \\
Macrophages \\
B cells \\
Neutrophils \\
\hline
\end{tabular}

\begin{tabular}{l}
\hline $\mathbf{O R}$ \\
\hline 1.0 \\
0.99 \\
0.99 \\
1.0 \\
1.0 \\
\\
0.97 \\
0.93 \\
1.0 \\
0.98 \\
1.0 \\
1.0 \\
0.96 \\
1.0 \\
1.2 \\
0.81 \\
2.6 \\
0.90 \\
2.3 \\
0.97 \\
0.75 \\
1.6 \\
\hline
\end{tabular}

\begin{tabular}{|c|c|}
\hline $95 \% \mathrm{Cl}$ & Pvalue \\
\hline $0.98-1.1$ & 0.24 \\
\hline $0.91-1.1$ & 0.86 \\
\hline $0.94-1.0$ & 0.67 \\
\hline $0.98-1.1$ & 0.35 \\
\hline $0.97-1.0$ & 0.87 \\
\hline $0.77-1.2$ & 0.75 \\
\hline $0.87-0.98$ & 0.014 \\
\hline $0.93-1.1$ & 0.96 \\
\hline $0.90-1.1$ & 0.65 \\
\hline $0.98-1.0$ & 0.59 \\
\hline $0.94-1.1$ & 0.87 \\
\hline $0.93-1.0$ & 0.029 \\
\hline $0.96-1.0$ & 0.81 \\
\hline $1.1-1.3$ & $3.7 \times 10^{-5}$ \\
\hline $0.45-1.3$ & 0.45 \\
\hline $1.5-4.5$ & $5.4 \times 10^{-4}$ \\
\hline $0.50-1.6$ & 0.73 \\
\hline $0.32-16$ & 0.41 \\
\hline $0.28-3.3$ & 0.96 \\
\hline $0.31-1.7$ & 0.50 \\
\hline $0.45-5.4$ & 0.47 \\
\hline
\end{tabular}

Tumor T stage is treated as a dichotomous variable. The odds ratio is presented as a $1 \%$ increase in immune cell fraction for CIBERSORT and a one-unit increase in the infiltration level for TIMER. Bold indicates statistical significance.
11 NIFTPs and 12 infiltrative FVPTCs to see if GAL3 correlated with more malignant or indolent tumor types. We scored GAL3 IHC intensity on a scale of $0-3$, where a score of zero indicated no staining, and a score of 3 indicated strong staining. The localization of the staining and score were used in conjunction to sort tumors into strong/diffuse GAL3 (diffuse 2-3+ staining), focal/ subcapsular GAL3 (focal 1-3+ staining) and GAL3 negative (0 staining) (Fig. 5B and C). Fifty-four percent (7/12) of the invasive FVPTCs demonstrated strong, diffuse staining compared to none $(0 / 11)$ of the NIFTPs. In contrast, none of the invasive FVPTCs were negative for GAL3, compared with $36 \%(4 / 11)$ of NIFTPs. Of note, the $7 / 11$ (55\%) of NIFTPs positive for GAL3 staining showed distribution that was distinct from that of invasive FVPTCs. Subcapsular staining with strong intensity $(2-3+)$, was identified in $45 \%(5 / 11)$ of NIFTPS and $17 \%(2 / 12)$ of invasive FVPTCs. The remaining $18 \%(2 / 11)$ of NIFTPs showed focal GAL3 positivity $(P=0.0019)$. These data demonstrate increased GAL3 in more invasive tumors and a distinct subcapsular or peripheral GAL3 staining in more indolent, and potentially pre-malignant, NIFTPs. This differential GAL3 expression confirms the GEPIA findings and is a potential mechanism for the T cell exclusive phenotype of papillary thyroid carcinomas.

\section{Discussion}

Until now, the specific immune cells involved in aggressive thyroid tumor behavior were unclear. Our study confirms previous reports that thyroid cancer immune infiltration is associated with BRAF mutations and adverse outcomes (Kim et al. 2018, Na \& Choi 2018) and expands upon these findings to identify specific immune cell subtypes associated with more aggressive tumor characteristics. In addition, we propose a mechanism for immune exclusion 

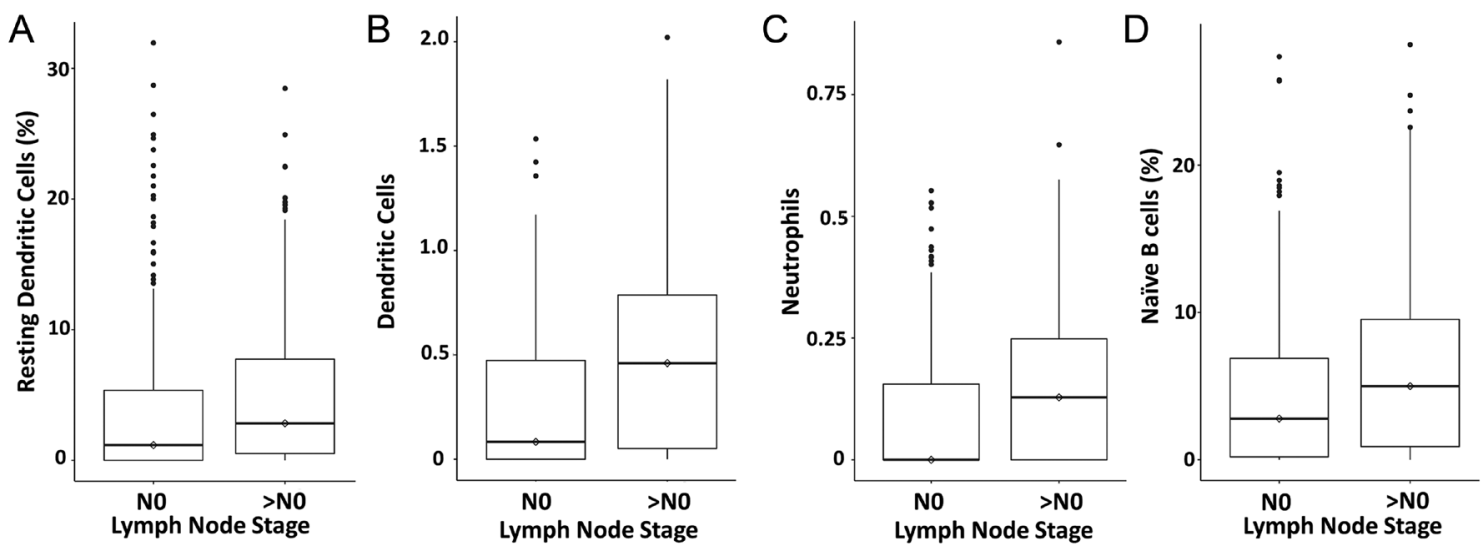

Figure 2

Distribution of immune cell fractions in tumors without (NO) and with (>NO) lymph node metastasis $(N=568)$. (A) ClBERSORT distribution of resting dendritic cells in tumors without (NO) and with (>NO) lymph node metastasis. (B) TIMER distribution of dendritic cells in tumors without (NO) and with (>NO) lymph node metastasis. (C) TIMER distribution of neutrophils in tumors without (NO) and with (>NO) lymph node metastasis. (D) CIBERSORT distribution of naïve B cells in tumors without (NO) and with (>NO) lymph node metastasis.

by dendritic cell infiltration and galectin 3 expression. We robustly define these immune cell types using three distinct deconvolution methodologies and assess multiple PTC characteristics using a large cohort of 568 tumors. The main immune cell types that are significantly associated with adverse PTC features across both deconvolution tools are macrophages, dendritic cells and neutrophils. Indeed, these innate immune cells significantly correlate with markers of aggressive disease such as BRAF mutation, tall cell morphology, increased tumor stage and LN metastases. This study also presents evidence for a role of lymphocytes in thyroid cancer anti-tumor immunity.

Studies in multiple tumor types provide support for the tumor-enhancing effect of dendritic cells, macrophages and neutrophils in thyroid cancer. PTCderived DCs may be responsible for regulatory T cell (Treg) differentiation and subsequent tumor immune evasion (Yu et al. 2013). Data in breast and other cancers suggest that immunosuppressive DCs correlate with metastatic disease and shorter survival (Treilleux et al. 2004). These dendritic cells may enhance metastasis through their role in enhancing angiogenesis and tumor vascularization (Curiel et al. 2004). Similar to DCs, tumor-associated macrophages (TAMs) are associated with more aggressive tumor behavior, larger tumor size, LN metastases and poor clinical outcome (Cunha et al. 2012, Kim 2013, Fang et al. 2014, Jung et al. 2015, Galdiero et al. 2016). Finally, neutrophils have been shown to be important for metastasis in multiple cancer types, including melanoma (Soler-Cardona et al. 2018), breast cancer (Wculek \& Malanchi 2015) and gastric cancer (Hiramatsu et al. 2018). Recent literature also suggests involvement of neutrophils
Table 5 Relationship of Immune cell fractions with pathologic tumor LN stage using CIBERSORT and TIMER $(N=568)$.

\begin{tabular}{l}
\hline LN stage \\
\hline CIBERSORT analysis \\
Naïve B cells \\
Memory B cells \\
Plasma cells \\
CD8 T cells \\
Resting CD4 memory \\
T cells \\
Activated CD4 \\
memory T cells \\
Follicular helper T \\
cells \\
Regulatory T cells \\
Gamma delta T cells \\
M0 macrophages \\
M1 macrophages \\
M2 macrophages \\
Resting dendritic \\
cells \\
Activated dendritic \\
cells \\
Neutrophils \\
TIMER analysis \\
DCs \\
CD8 T cells \\
CD4 T cells \\
Macrophages \\
B cells \\
Neutrophils \\
\hline
\end{tabular}

\begin{tabular}{|c|c|c|}
\hline OR & $95 \% \mathrm{Cl}$ & $P$ value \\
\hline 1.1 & $1.0-1.1$ & $5.2 \times 10^{-4}$ \\
\hline 1.1 & $0.97-1.2$ & 0.16 \\
\hline 1.0 & $0.98-1.1$ & 0.30 \\
\hline 1.0 & $0.96-1.0$ & 0.83 \\
\hline 1.0 & $0.99-1.1$ & 0.20 \\
\hline 0.97 & $0.78-1.2$ & 0.82 \\
\hline 1.0 & $0.96-1.1$ & 0.55 \\
\hline 1.0 & $0.92-1.1$ & 0.91 \\
\hline 1.1 & $0.97-1.2$ & 0.18 \\
\hline 1.0 & $1.0-1.1$ & 0.021 \\
\hline 1.0 & $0.94-1.1$ & 0.89 \\
\hline 1.0 & 0.97-1.0 & 0.87 \\
\hline 1.1 & $1.0-1.1$ & 0.019 \\
\hline 1.1 & $0.99-1.2$ & 0.076 \\
\hline 1.9 & $1.0-4.1$ & 0.067 \\
\hline 3.4 & $1.9-6.3$ & $5.5 \times 10^{-5}$ \\
\hline 2.1 & $1.1-4.0$ & 0.029 \\
\hline 0.69 & $0.087-5.4$ & 0.72 \\
\hline 0.59 & $0.15-2.2$ & 0.43 \\
\hline 2.3 & $1.0-5.7$ & 0.054 \\
\hline 10.5 & $2.7-44$ & $8.7 \times 10^{-4}$ \\
\hline
\end{tabular}

LN stage is treated as a dichotomous variable. The odds ratio is presented as a $1 \%$ increase in immune cell fraction for CIBERSORT and a one-unit increase in the infiltration level for TIMER. Bold indicates statistical significance.
2019 Society for Endocrinology Published by Bioscientifica Ltd. Printed in Great Britain 
A

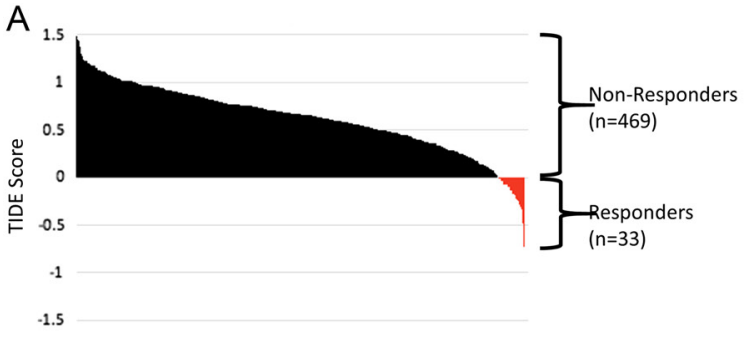

C

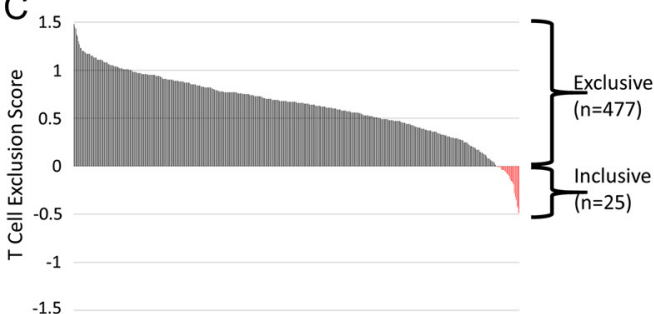

$\mathrm{B}_{1.5}$

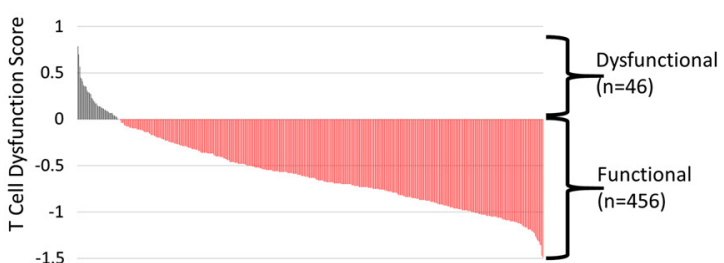

D
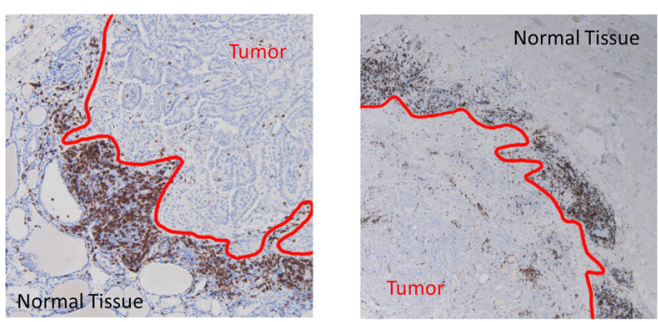

\section{Figure 3}

Tumor immune dysfunction and exclusion (TIDE) analysis $(N=568)$. (A) Overall TIDE scores and predicted tumor response to checkpoint blockade. (B) TIDE dysfunction score. DS $>0$ indicates T cell dysfunction, DS $<0$ indicates functional T cells. (C) TIDE T cell exclusion score. ES $>0$ indicates an T cell exclusive tumor, ES $<0$ indicates a T cell inclusive tumor. (D) IHC of patient tumors, with CD8+ T cells shown in black.

in the growth of thyroid carcinomas (Galdiero et al. 2018). While the mechanism of neutrophil-mediated enhancement of metastasis is unclear, some studies suggest that neutrophils inhibit CD8 $\mathrm{T}$ cells and may attract metastatic cells to new sites (Coffelt et al. 2015, Wculek \& Malanchi 2015). Our data support the role of these innate immune cells in enhancing metastatic behavior in thyroid cancer.
Studies in multiple tumor types also suggest an important role for lymphocytes in anti-tumor immunity. In our study, a subset of tumors in the TCGA cohort demonstrate a potential anti-tumor infiltrate, the follicular helper $\mathrm{T}$ cells $\left(\mathrm{T}_{\mathrm{FH}}\right)$. Other studies suggest that $\mathrm{T}_{\mathrm{FH}}$ cells are essential in anti-tumoral immune recruitment and for the formation of tertiary lymphoid structures (TLS), which may be involved in $\mathrm{T}$ cell priming and $\mathrm{B}$ cell trafficking
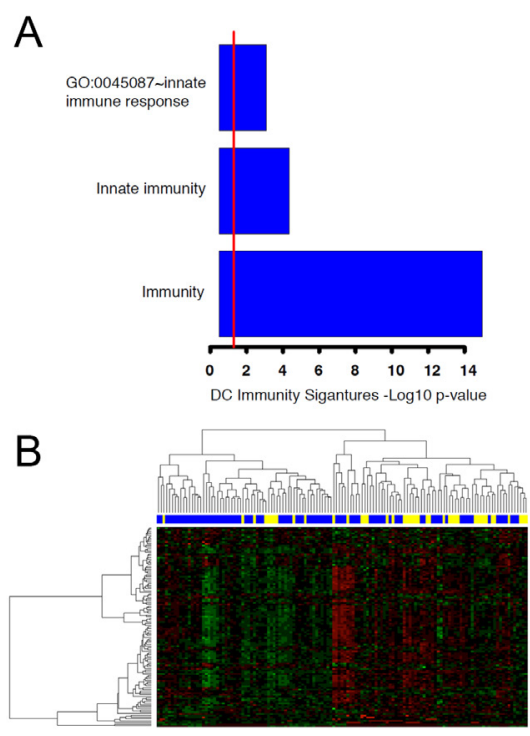

C

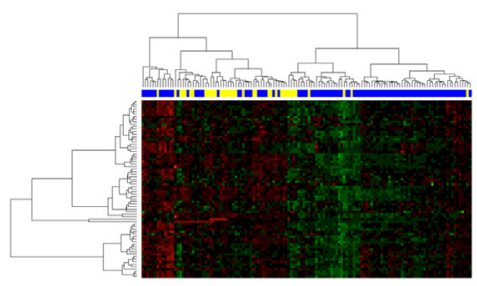

D

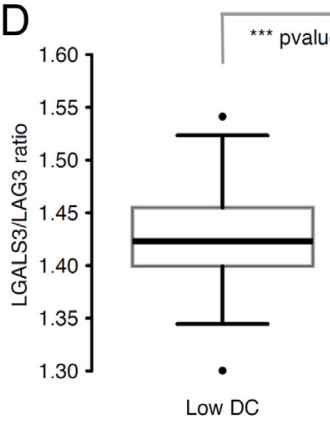

Figure 4

Immune gene expression in activated DC high PTCs $(N=131)$. (A) Negative $\log _{10}$ of the FDR value for pathway enrichment for terms in the top cluster from DAVID analysis of differentially expressed genes between low and high activated DC thyroid samples. Red line marks $P$ value of 0.05. (B) Heatmap of the differentially expressed genes from DC-enriched immunity signature. Green is high expression and red is low expression. Yellow marks high activated DC and blue marks low activated DC tumors. Most high activated DC samples are in the cluster with predominately low expression of the genes in the immune signature. (C) Heatmap of differentially expressed genes from $T_{F H}$ enriched immunity signature. Green is high expression and red is low expression. Yellow marks low $\mathrm{T}_{\mathrm{FH}}$ and blue marks high $\mathrm{T}_{\mathrm{FH}}$. Most high $\mathrm{T}_{\mathrm{FH}}$ samples are in the cluster with predominately high expression of the genes in the immunity signature. (D) Ratio of LGALS3 to LAG3 in activated DC low and high samples $\left(P=5.47 \times 10^{-10}\right.$, Wilcoxon rank test). Samples that had $P \geq 0.05$ in CIBERSORT were excluded from this analysis. 
A

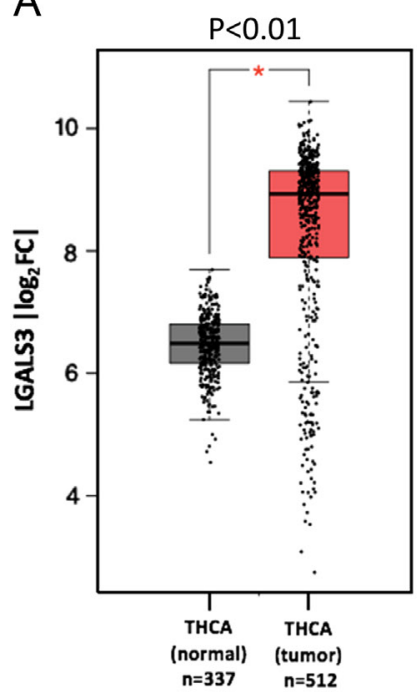

B NIFTP
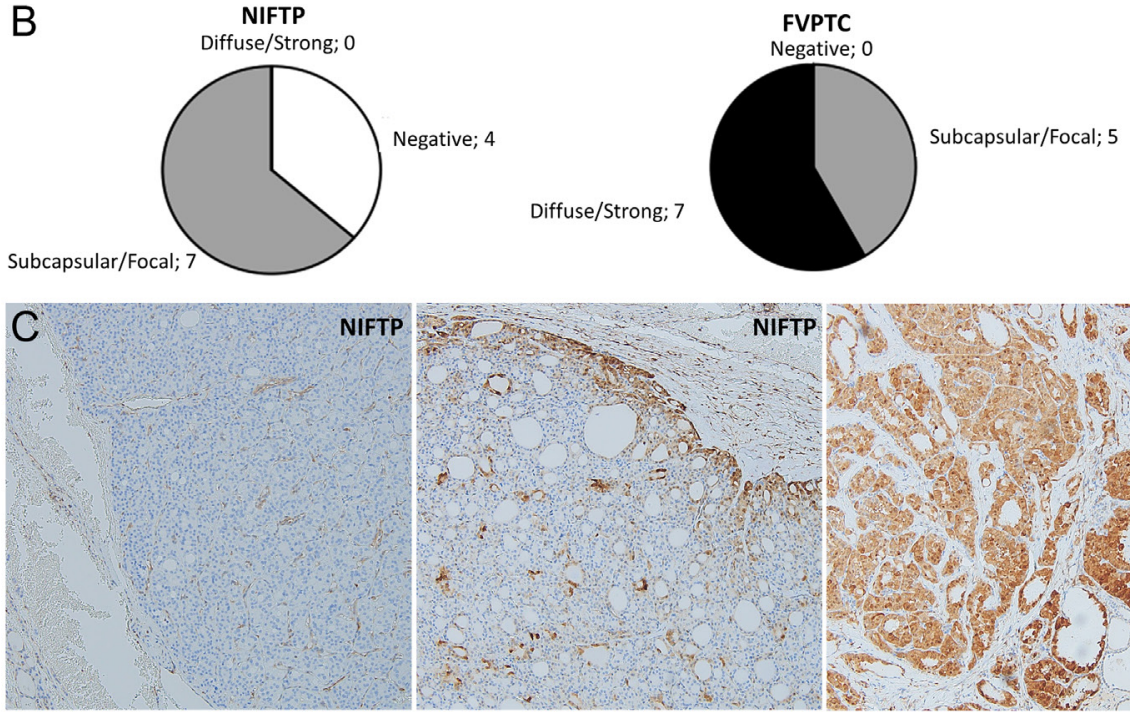

Diffuse/Strong; 7
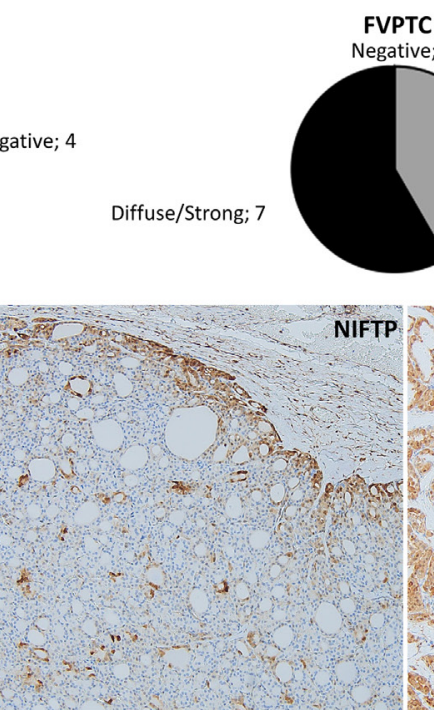

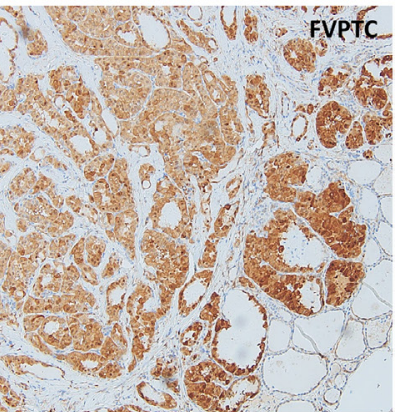

Figure 5

GAL3 expression in NIFTPs and infiltrative FVPTCs $(N=502)$. (A) GEPIA analysis of LGALS3 expression in TCGA THCA ( $P<0.01)$. Statistical analysis performed in GEPIA is a one-way ANOVA, using disease state as a variable for calculating differential expression. (B) Tumor morphology was evaluated and tumors were stained for GAL3 expression ( $P=0.0019)$, 100× magnification. (C) Representative IHC images of GAL3 staining (left-negative; middlesubcapsular; right-strong/diffuse).

via CXCR5 expression (McHeyzer-Williams et al. 2011, Vinuesa \& Cyster 2011, Gu-Trantien \& Willard-Gallo 2013, Dieu-Nosjean et al. 2016). The presence of $\mathrm{T}_{\mathrm{FH}}$ cells and TLS are thought to be good prognostic markers in many tumors, including breast cancer (Gu-Trantien et al. 2013), where it has been shown to be associated with a higher overall survival and increased response to neoadjuvant chemotherapy (Ali et al. 2016, Bense et al. 2017). Our data suggest that this protective function may be present within a subset of PTC tumors.

In deciphering a mechanism of tumor immunosuppression, we evaluated both the degree of $\mathrm{T}$ cell dysfunction within our tumors and the immune gene signatures present in DC-rich lesions. The vast majority of PTCs in the TCGA cohort have gene signatures consistent with T cell exclusion. This T cell exclusion may be due to the presence of immunosuppressive DCs and macrophages. Evaluation of the TCGA PTC cohort demonstrates an overall decreased immune signature in DC-rich PTCs, suggesting an immunosuppressive or immune-exclusive role in thyroid cancer. One potential mechanism of $\mathrm{T}$ cell exclusion is the interaction of LAG3 and GAL3. Studies have shown that the interaction between LAG3 and GAL3 in the tumor microenvironment leads to T cell suppression (Kouo et al. 2015) and that the recruitment of T cells may be decreased in GAL3-high tumors (GordonAlonso et al. 2017). In assessing the immune signatures of DC low and high tumors, we find that the LGALS3/LAG3 ratio is significantly higher in activated DC high tumors, suggesting that this may be a potential mechanism for the immune exclusion environment. Indeed, in PTCs, GAL3 expression by the tumor may decrease $\mathrm{T}$ cell recruitment and inhibit the formation of inflammatory DCs in the tumor microenvironment via LAG3 (Kouo et al. 2015, Gordon-Alonso et al. 2017). Evaluation of our institutional PTC and NIFTP cohort confirms the increased GAL3 in infiltrative FVPTCs and the exclusion of T cells to the PTC periphery. In addition to GAL3, chemokines likely also function in the establishment of an immunosuppressive tumor microenvironment. Certain chemokines such as CXCL6, CXCL8 and CXCL20 are known to be highly expressed in aggressive thyroid cancers and have protumorigenic functions including the recruitment of macrophages and dendritic cells in the tumor (Yapa et al. 2017, Rotondi et al. 2018). Future studies are needed to discover a potential therapeutic role for inhibitors of these protumorigenic mediators.

While this study uses a robust cohort and two stateof-the-art deconvolution tools for defining immune infiltrates, there are several limitations to a computational approach. One limitation to this study is that the two analytic tools occasionally demonstrate some conflicting results, likely based on their different computational approaches, pre-defined immune gene signatures, numbers of immune subsets and data output format. This can cause issues with the direct comparison of results. 
CIBERSORT provides an analysis of 22 immune cell subtypes. However, the method of defining these subtypes, such as M1 and M2 macrophages is controversial, and it is possible that false positives for each group were included in the output due to overlapping gene expression. This may also be the case with Treg cells, as both activated $\mathrm{T}_{\mathrm{FH}}$ (Gu-Trantien \& Willard-Gallo 2013, Gu-Trantien et al. 2013) and PTC tumor cells (Karanikas et al. 2008, Ugolini et al. 2014) have been shown to express FoxP3 (an important Treg marker). This may explain why few significant Treg correlations were seen in this study using CIBERSORT, despite evidence that Tregs are important in many cancer types. Another issue is that CIBERSORT, while providing overall $P$ values for each tumor, does not provide $P$ values for each individual immune cell fraction. TIMER also provides no significance data for its immune cell calculations. These issues reveal a need for additional complex immune subset analyses, particularly for rare immune cell infiltrates, to confirm the results of computational analyses. It is also important to note that the staging data provided by TCGA is from AJCC edition 7, recently replaced by AJCC edition 8, wherein some previously high-stage tumors would now be classified as lower stage. Although we are unable to re-stage the TCGA tumors, the previous staging method still provides useful qualitative information on the presence of microscopic extra-thyroidal extension and LN metastasis.

Here, we present a computational evaluation of immune cell infiltrates in PTCs and show that the presence of certain cell types, particularly dendritic cells and neutrophils, strongly correlate with histologic subtype, mutational status, T stage, and LN metastases. We also demonstrate an immune exclusion phenotype of PTCs that may be dependent on a GAL3- and LAG3mediated mechanism of immune suppression and $\mathrm{T}$ cell exclusion. Further studies that include poorly differentiated thyroid carcinomas will allow for a better understanding of the role of immune cells in thyroid cancer progression and survival. In addition, an understanding of the specific immune composition of thyroid cancers may provide prognostic information and lead to the development of novel targeted therapies for advanced disease.

\section{Supplementary data}

This is linked to the online version of the paper at https://doi.org/10.1530/ ERC-19-0074.

\section{Declaration of interest}

The authors declare that there is no conflict of interest that could be perceived as prejudicing the impartiality of the research reported.

\section{Funding}

Funding for this project was provided by the American Society of Cytopathology Foundation Young Investigator Grant.

\section{Acknowledgements}

The autors would like to acknowledge the Translational Pathology Shared Resource supported by $\mathrm{NCI} / \mathrm{NIH}$ Cancer Center Support Grant 5P30 CA68485-19 and the Vanderbilt Mouse Metabolic Phenotyping Center Grant 2 U24 DK059637-16, and the Shared Instrumental Grant S10 OD023475-01A1 for the Leica Bond RX.

\section{Author contribution statement}

V L W, T S, D C F and K B performed the computational analysis, reviewed the clinicopathologic data and wrote the manuscript. K E and $\mathrm{M} \mathrm{M}$ reviewed the histology, scored the immunohistochemistry and reviewed the manuscript.

\section{References}

Abbas AR, Baldwin D, Ma Y, Ouyang W, Gurney A, Martin F, Fong S, van Lookeren Campagne M, Godowski P, Williams PM, et al. 2005 Immune response in silico (IRIS): immune-specific genes identified from a compendium of microarray expression data. Genes and Immunity 6 319-331. (https://doi.org/10.1038/sj.gene.6364173)

Ali HR, Chlon L, Pharoah PD, Markowetz F \& Caldas C 2016 Patterns of immune infiltration in breast cancer and their clinical implications: A gene-expression-based retrospective study. PLoS Medicine 13 e1002194. (https://doi.org/10.1371/journal.pmed.1002194)

Bense RD, Sotiriou C, Piccart-Gebhart MJ, Haanen JBAG, Van Vugt MATM, De Vries EGE, Schroder CP \& Fehrmann RSN 2017 Relevance of tumor-infiltrating immune cell composition and functionality for disease outcome in breast cancer. Journal of the National Cancer Institute 109. (https://doi.org/10.1093/jnci/djw192)

Chiu CG, Strugnell SS, Griffith OL, Jones SJ, Gown AM, Walker B, Nabi IR \& Wiseman SM 2010 Diagnostic utility of galectin-3 in thyroid cancer. American Journal of Pathology 176 2067-2081. (https://doi.org/10.2353/ajpath.2010.090353)

Coffelt SB, Kersten K, Doornebal CW, Weiden J, Vrijland K, Hau CS, Verstegen NJM, Ciampricotti M, Hawinkels LJAC, Jonkers J, et al. 2015 IL-17-producing gammadelta T cells and neutrophils conspire to promote breast cancer metastasis. Nature 522 345-348. (https:// doi.org/10.1038/nature14282)

Cunha LL, Morari EC, Guihen AC, Razolli D, Gerhard R, Nonogaki S, Soares FA, Vassallo J \& Ward LS 2012 Infiltration of a mixture of immune cells may be related to good prognosis in patients with differentiated thyroid carcinoma. Clinical Endocrinology 77 918-925. (https://doi.org/10.1111/j.1365-2265.2012.04482.x)

Cunha LL, Marcello MA, Nonogaki S, Morari EC, Soares FA, Vassallo J \& Ward LS 2015 CD8+ tumour-infiltrating lymphocytes and COX2 expression may predict relapse in differentiated thyroid cancer. Clinical Endocrinology 83 246-253. (https://doi.org/10.1111/ cen.12586)
(C) 2019 Society for Endocrinology Published by Bioscientifica Ltd. Printed in Great Britain 
Curiel TJ, Cheng P, Mottram P, Alvarez X, Moons L, Evdemon-Hogan M, Wei S, Zou L, Kryczek I, Hoyle G, et al. 2004 Dendritic cell subsets differentially regulate angiogenesis in human ovarian cancer. Cancer Research 64 5535-5538. (https://doi.org/10.1158/0008-5472.CAN-041272)

Dieu-Nosjean MC, Giraldo NA, Kaplon H, Germain C, Fridman WH \& Sautes-Fridman C 2016 Tertiary lymphoid structures, drivers of the anti-tumor responses in human cancers. Immunological Reviews $\mathbf{2 7 1}$ 260-275. (https://doi.org/10.1111/imr.12405)

Fang W, Ye L, Shen L, Cai J, Huang F, Wei Q, Fei X, Chen X, Guan H, Wang W, et al. 2014 Tumor-associated macrophages promote the metastatic potential of thyroid papillary cancer by releasing CXCL8. Carcinogenesis 35 1780-1787. (https://doi.org/10.1093/carcin/bgu060)

French JD, Weber ZJ, Fretwell DL, Said S, Klopper JP \& Haugen BR 2010 Tumor-associated lymphocytes and increased FoxP3+ regulatory $\mathrm{T}$ cell frequency correlate with more aggressive papillary thyroid cancer. Journal of Clinical Endocrinology and Metabolism 95 2325-2333. (https://doi.org/10.1210/jc.2009-2564)

Galdiero MR, Varricchi G \& Marone G 2016 The immune network in thyroid cancer. Oncoimmunology 5 e1168556. (https://doi.org/10.108 0/2162402X.2016.1168556)

Galdiero MR, Varricchi G, Loffredo S, Bellevicine C, Lansione T, Ferrara AL, Iannone R, Di Somma S, Borriello F, Clery E, et al. 2018 Potential involvement of neutrophils in human thyroid cancer. PLoS ONE 13 e0199740. (https://doi.org/10.1371/journal.pone.0199740)

Gordon-Alonso M, Hirsch T, Wildmann C \& Van Der Bruggen P 2017 Galectin-3 captures interferon-gamma in the tumor matrix reducing chemokine gradient production and T-cell tumor infiltration. Nature Communications 8 793. (https://doi.org/10.1038/s41467-017-00925-6)

Gu-Trantien C \& Willard-Gallo K 2013 Tumor-infiltrating follicular helper T cells: the new kids on the block. Oncoimmunology 2 e26066. (https://doi.org/10.4161/onci.26066)

Gu-Trantien C, Loi S, Garaud S, Equeter C, Libin M, De Wind A, Ravoet M, Le Buanec H, Sibille C, Manfouo-Foutsop G, et al. 2013 CD4(+) follicular helper T cell infiltration predicts breast cancer survival. Journal of Clinical Investigation 123 2873-2892. (https://doi. org/10.1172/JCI67428)

Hendry S, Salgado R, Gevaert T, Russell PA, John T, Thapa B, Christie M, Van De Vijver K, Estrada MV, Gonzalez-Ericsson PI, et al. 2017a Assessing tumor-infiltrating lymphocytes in solid tumors: a practical review for pathologists and proposal for a standardized method from the International Immuno-Oncology Biomarkers Working Group. Part 2: TILs in melanoma, gastrointestinal tract carcinomas, nonsmall cell lung carcinoma and mesothelioma, endometrial and ovarian carcinomas, squamous cell carcinoma of the head and neck, genitourinary carcinomas, and primary brain tumors. Advances in Anatomic Pathology 24 311-335. (https://doi.org/10.1097/ PAP.0000000000000161)

Hendry S, Salgado R, Gevaert T, Russell PA, John T, Thapa B, Christie M, Van De Vijver K, Estrada MV, Gonzalez-Ericsson PI, et al. 2017b Assessing tumor-infiltrating lymphocytes in solid tumors: a practical review for pathologists and proposal for a standardized method from the International Immunooncology Biomarkers Working Group. Part 1: Assessing the host immune response, TILs in invasive breast carcinoma and ductal carcinoma in situ, metastatic tumor deposits and areas for further research. Advances in Anatomic Pathology 24 235-251. (https://doi.org/10.1097/PAP.0000000000000162)

Hiramatsu S, Tanaka H, Nishimura J, Sakimura C, Tamura T, Toyokawa T, Muguruma K, Yashiro M, Hirakawa K \& Ohira M 2018 Neutrophils in primary gastric tumors are correlated with neutrophil infiltration in tumor-draining lymph nodes and the systemic inflammatory response. BMC Immunology 19 13. (https://doi.org/10.1186/s12865-018-0251-2)

Jiang P, Gu S, Pan D, Fu J, Sahu A, Hu X, Li Z, Traugh N, Bu X, Li B, et al. 2018 Signatures of $\mathrm{T}$ cell dysfunction and exclusion predict cancer immunotherapy response. Nature Medicine 24 1550-1558. (https://doi.org/10.1038/s41591-018-0136-1)
Jung KY, Cho SW, Kim YA, Kim D, Oh BC, Park DJ \& Park YJ 2015 Cancers with higher density of tumor-associated macrophages were associated with poor survival rates. Journal of Pathology and Translational Medicine 49 318-324. (https://doi.org/10.4132/jptm.2015.06.01)

Karanikas V, Speletas M, Zamanakou M, Kalala F, Loules G, Kerenidi T, Barda AK, Gourgoulianis KI \& Germenis AE 2008 Foxp3 expression in human cancer cells. Journal of Translational Medicine 6 19. (https:// doi.org/10.1186/1479-5876-6-19)

Kim BH 2013 The expression of tumor-associated macrophages in papillary thyroid carcinoma. Endocrinology and Metabolism 28 178-179. (https://doi.org/10.3803/EnM.2013.28.3.178)

Kim K, Jeon S, Kim TM \& Jung CK 2018 Immune gene signature delineates a subclass of papillary thyroid cancer with unfavorable clinical outcomes. Cancers 10 494. (https://doi.org/10.3390/ cancers10120494)

Kouo T, Huang L, Pucsek AB, Cao M, Solt S, Armstrong T \& Jaffee E 2015 Galectin-3 shapes antitumor immune responses by suppressing CD8+ T cells via LAG-3 and inhibiting expansion of plasmacytoid dendritic cells. Cancer Immunology Research 3 412-423. (https://doi. org/10.1158/2326-6066.CIR-14-0150)

Li B, Severson E, Pignon JC, Zhao H, Li T, Novak J, Jiang P, Shen H, Aster JC, Rodig S, et al. 2016 Comprehensive analyses of tumor immunity: implications for cancer immunotherapy. Genome Biology 17 174. (https://doi.org/10.1186/s13059-016-1028-7)

Li T, Fan J, Wang B, Traugh N, Chen Q, Liu JS, Li B \& Liu XS 2017 TIMER: A web server for comprehensive analysis of tumorinfiltrating immune cells. Cancer Research 77 e108-e110. (https://doi. org/10.1158/0008-5472.CAN-17-0307)

Lundgren CI, Hall P, Dickman PW \& Zedenius J 2006 Clinically significant prognostic factors for differentiated thyroid carcinoma: a population-based, nested case-control study. Cancer 106 524-531. (https://doi.org/10.1002/cncr.21653)

Matsubayashi S, Kawai K, Matsumoto Y, Mukuta T, Morita T, Hirai K, Matsuzuka F, Kakudoh K, Kuma K \& Tamai H 1995 The correlation between papillary thyroid carcinoma and lymphocytic infiltration in the thyroid gland. Journal of Clinical Endocrinology and Metabolism 80 3421-3424. (https://doi.org/10.1210/ jcem.80.12.8530576)

Mcheyzer-Williams M, Okitsu S, Wang N \& Mcheyzer-Williams L 2011 Molecular programming of B cell memory. Nature Reviews Immunology 12 24-34. (https://doi.org/10.1038/nri3128)

Na KJ \& Choi H 2018 Immune landscape of papillary thyroid cancer and immunotherapeutic implications. Endocrine-Related Cancer $\mathbf{2 5}$ 523-531. (https://doi.org/10.1530/ERC-17-0532)

Newman AM, Liu CL, Green MR, Gentles AJ, Feng W, Xu Y, Hoang CD, Diehn M \& Alizadeh AA 2015 Robust enumeration of cell subsets from tissue expression profiles. Nature Methods 12 453-457. (https:// doi.org/10.1038/nmeth.3337)

Nikiforov YE, Seethala RR, Tallini G, Baloch ZW, Basolo F, Thompson LD, Barletta JA, Wenig BM, Al Ghuzlan A, Kakudo K, et al. 2016 Nomenclature revision for encapsulated follicular variant of papillary thyroid carcinoma: a paradigm shift to reduce overtreatment of indolent tumors. JAMA Oncology 2 1023-1029. (https://doi.org/10.1001/jamaoncol.2016.0386)

Qing W, Fang WY, Ye L, Shen LY, Zhang XF, Fei XC, Chen X, Wang WQ, Li XY, Xiao JC, et al. 2012 Density of tumor-associated macrophages correlates with lymph node metastasis in papillary thyroid carcinoma. Thyroid 22 905-910. (https://doi.org/10.1089/ thy.2011.0452)

Rahib L, Smith BD, Aizenberg R, Rosenzweig AB, Fleshman JM \& Matrisian LM 2014 Projecting cancer incidence and deaths to 2030: the unexpected burden of thyroid, liver, and pancreas cancers in the United States. Cancer Research 74 2913-2921. (https://doi. org/10.1158/0008-5472.CAN-14-0155)

Rotondi M, Coperchini F, Latrofa F \& Chiovato L 2018 Role of chemokines in thyroid cancer microenvironment: is CXCL8 the 
main player? Frontiers in Endocrinology 9 314. (https://doi. org/10.3389/fendo.2018.00314)

Ryder M, Ghossein RA, Ricarte-Filho JC, Knauf JA \& Fagin JA 2008 Increased density of tumor-associated macrophages is associated with decreased survival in advanced thyroid cancer. Endocrine-Related Cancer 15 1069-1074. (https://doi.org/10.1677/ERC-08-0036)

Soler-Cardona A, Forsthuber A, Lipp K, Ebersberger S, Heinz M, Schossleitner K, Buchberger E, Groger M, Petzelbauer P, Hoeller C, et al. 2018 CXCL5 facilitates melanoma cell-neutrophil interaction and lymph node metastasis. Journal of Investigative Dermatology 138 1627-1635. (https://doi.org/10.1016/j.jid.2018.01.035)

Tang Z, Li C, Kang B, Gao G, Li C \& Zhang Z 2017 GEPIA: a web server for cancer and normal gene expression profiling and interactive analyses. Nucleic Acids Research 45 W98-W102. (https://doi. org/10.1093/nar/gkx247)

Treilleux I, Blay JY, Bendriss-Vermare N, Ray-Coquard I, Bachelot T, Guastalla JP, Bremond A, Goddard S, Pin JJ, Barthelemy-Dubois C, et al. 2004 Dendritic cell infiltration and prognosis of early stage breast cancer. Clinical Cancer Research 10 7466-7474. (https://doi. org/10.1158/1078-0432.CCR-04-0684)
Tsuge K, Takeda H, Kawada S, Maeda K \& Yamakawa M 2005 Characterization of dendritic cells in differentiated thyroid cancer. Journal of Pathology 205 565-576. (https://doi.org/10.1002/path.1731)

Ugolini C, Elisei R, Proietti A, Pelliccioni S, Lupi C, Borrelli N, Viola D, Leocata P, Vitti P, Miccoli P, et al. 2014 FoxP3 expression in papillary thyroid carcinoma: a possible resistance biomarker to iodine 131 treatment. Thyroid 24 339-346. (https://doi.org/10.1089/thy.2012.0589)

Vinuesa CG \& Cyster JG 2011 How T cells earn the follicular rite of passage. Immunity 35 671-680. (https://doi.org/10.1016/j. immuni.2011.11.001)

Wculek SK \& Malanchi I 2015 Neutrophils support lung colonization of metastasis-initiating breast cancer cells. Nature 528 413-417. (https://doi.org/10.1038/nature16140)

Yapa S, Mulla O, Green V, England J \& Greenman J 2017 The role of chemokines in thyroid carcinoma. Thyroid 27 1347-1359. (https:// doi.org/10.1089/thy.2016.0660)

Yu H, Huang X, Liu X, Jin H, Zhang G, Zhang Q \& Yu J 2013 Regulatory $\mathrm{T}$ cells and plasmacytoid dendritic cells contribute to the immune escape of papillary thyroid cancer coexisting with multinodular nontoxic goiter. Endocrine 44 172-181. (https://doi.org/10.1007/s12020012-9853-2)

Received in final form 1 April 2019

Accepted 9 April 2019

Accepted Preprint published online 9 April 2019 (c) 2019 Society for Endocrinology Published by Bioscientifica Ltd. Printed in Great Britain 